\title{
DEFINISANJE KARAKTERISTIKA SNOW \& RAIN ŠUMA DIGITALNE SLIKE METODOM PARCIJALNOG FILTRIRANJA
}

\author{
Ratko Ivkovicín, \\ Ivana Milošević \\ Branimir Jakšić ${ }^{1}$ \\ Petar Spalević, \\ Mirko Milošević ${ }^{3}$
}

\author{
${ }^{1}$ Fakultet Tehničkih Nauka, \\ Univerzitet u Prištini, \\ Kosovska Mitrovica, Srbija \\ 2Univerzitet Singidunum, \\ Beograd, Srbija \\ ${ }^{3}$ Visoka škola elektrotehnike i računarstva, \\ Beograd, Srbija
}

\begin{abstract}
Rezime:
Sa sve većom primenom digitalne slike u raznim oblastima nauke javljaju se i novi izazovi za obradu. Nove osobine slike potrebno je valjano obraditi i opisati posmatrajući ih iz više uglova bazirajući se na teorijska razmatranja. Ovaj rad definiše karakteristike Snow \& Rain šuma digitalne slike metodom parcijalnog filtriranja i pruža jedan od modela za detektovanje vrste i koncentracije šuma u digitalnoj slici. Rezultati su prikazani grafički i numerički nakon obrade više od 50 digitalnih slika, a tretirani su adekvatnim parametrima za ocenu kvaliteta.
\end{abstract}

Ključne reči:

Digitalna Obrada Slike, Šumovi, Snow \& Rain, Parcijalno filtriranje, Median filter.

\section{UVOD}

Iako se definiše kao osnovni element multimedije, digitalna slika posmatrana kao jedinstveni signal nije izuzeta od ostalih karakteristika definisanih za signale. Bilo da se radi o procesu kreiranja signala, prenosa ili obrade, mora da postoji sinhronizacija između njih koja nema idealne karakteristike. Sa druge strane, svaki postupak definiše pozitivne i negativne osobine signala. Samim tim, digitalna slika se još uvek ne može smatrati idealnim signalom, a možda jedan od najčvršćih dokaza nesavršenosti digitalne slike jeste postojanje šumova, odnosno nečistoća u slici. Definisana kao signal, slika se opisuje kroz parametre definisane za digitalnu obradu signala, a u tom slučaju šumovi se definišu uz pomoć funkcija raspodela [1]. Drugim rečima, šum u slici je definisan nekom od funkcija raspodele, pa se tako razlikuju Lorencov, Laplasov, Gausov itd [2]. Kasnija procesiranja digitalne slike kroz prostorni domen dala su novu dimenziju rezultatima obrade i analize.

Međutim, uprkos brojnim radovima stiče se utisak da je nedostajala komponeta analize šumova kroz prostorni 2D domen. Veoma je teško analizirati tako nešto jer se piksel predstavlja kao vrednost boje u nekoj bitskoj skali za tri različita kanala, pa bi za veći stepen šuma učestalost promene boje mogla da se tretira kao povećanje nivoa detalja, dok bi entropija bila na višem nivou, što bi dovelo do greške u analizi. Bez obzira na ovu činjenicu danas, filteri koji se zasnivaju na prostornoj analizi
Odgovorno lice:

Ratko Ivković

e-pošta:

ratko.ivkovic@pr.ac.rs 
daju značajno bolje rezultate za razliku od frekvencijske. Suština rada ovakvih filtera se zasniva na nekoj od ideja usrednjavanja ili zamene okoline posmatranog piksela.

Metoda parcijalnog filtriranja digitalne slike pruža mogućnost da se različiti segmenti slike podvrgnu različitim stepenima filtriranja, različitim vrstama filtriranja ili izuzeti iz procesa dodatne obrade [3].

Sa druge strane novi tipovi šumova koji se mogu naći u digitalnim slikama se tretiraju kao kombinacija elementarnih tipova šumova u digitalnoj slici. Jako je bitno detaljno opisati nove tipove šumova i striktno ih vezati za uslove u kojima se mogu javiti. Veoma je bitno napomenuti da kod Snow \& Rain šuma elementi šuma su poznati $[4,5]$. Karakteristike ovog šuma se mogu tretirati kao sastavni delovi slike koji markiraju određene elemente digitalne slike, ali ne utiču na ostali deo slike. Upravo zbog ovog razloga se ova vrsta šuma treba tretirati na poseban način i definisati kroz već definisane vrste šumova.

\section{TEORIJSKE OSNOVE}

Iako se vizuelno teže raspoznaju, matematika donekle pruža preciznije odgovore na razlike između definisanih šumova. Međutim, ako se porede Slika a i Slika b sa grafikona 1, ne može se doći do ovakvog zaključka. Naime, na grafikonu 1a se nalazi distribucija Poisson šuma, a na grafikonu $1 \mathrm{~b}$ je predstavljena Gausova raspodela na digitalnoj slici. Matematički rečeno stepen distribucije Poisson i Gausovog šuma se poklapaju oko $95 \%$, pa se može steći utisak da se radi o identičnoj vrsti šuma [6]. Međutim, Poisson šum se definiše kao greška računanja fotona pri kreiranju slike.

U realnim situacijama fotoni dolaze u snopovim, pa je sasvim logično da svi snopovi nemaju identičnu koncentraciju fotona. Greška koja nastaje prilikom kreiranja slike je definisana razlikom u prikupljenim fotonima i definisana kroz Poisson raspodelu.

a)

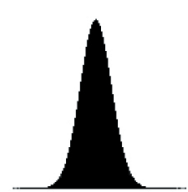

b)

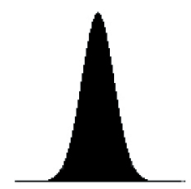

Slika 1. Prikaz a) Poisson noise, b) Gauss noise

Šum ove vrste zavisi od osetljivosti senzora i definiše grešku do 5\% skale zapisa, kako je već definisano $[7,8]$, dok se sa druge strane Gausov šum može javiti u svim procesima kojima podleže digitalna slika, od kreiranja, preko prenosa i obrade. Sa druge strane, ne definiše se kao u prethodnom slučaju, već može zauzeti puno širi spektar u zavisnosti od procesa koji utiče na sliku.

Pri istom stepenu distribucije, Slika 1 prikazuje razliku između dva opisana šuma, pri čemu leva polovina slike prikazuje Poisson, a desna polovina Gauss šum. Iako je gotovo identična distribucija, Gauss šum više „kvari” kvalitet slike, što bi se trebalo dodatno analizirati.

a)

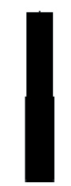

b)

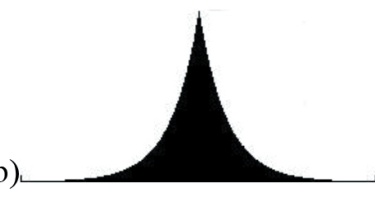

Slika 2. Prikaz a) Uniform noise, b) Laplace noise

Poređenje Uniform i Laplace šuma je lakše objasniti, iako se na slici vizuelno teže razlikuju, što pokazuje Slika 2 , gde su pri istoj distribuciji šuma prikazani pomenuti šumovi. Iako je površina ispod krive na Grafikonu 2a i b identična, zbog širine spektra koju pokriva čini se da Laplace pokazuje malo veći intenzitet.

Uniform šum se izuzetno retko javlja u prirodi, ali u procesu digitalizacije slike uglavnom se javlja kao signal greške koji je ravnomerno raspoređen, a za razliku od Gauss šuma ne zavisi od intenziteta slike, pa iz tog razloga se ne može naći u procesu kreiranja digitalne slike [9, 10]. Laplace šum se odlikuje sa dvostrukom eksponencijalnom distribucijom. Takođe je bitno napomenuti da Laplace šum mže da nastane u svim procesima gde može da figurira digitalna slika, pa nastaje kao rezultat ili međuprocesa ili kao sporedni efekat samog procesa [11].

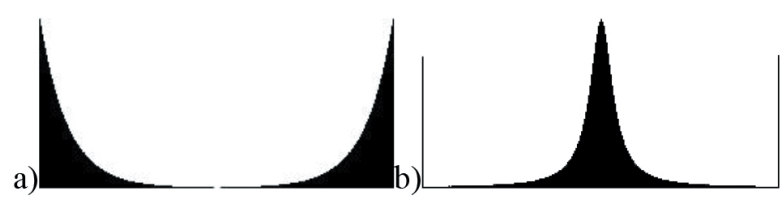

Slika 3. Prikaz a) Salt \& Papper noise, b) Lorentz noise

Lorentz šum, kao što je prikazano na Grafikonu 3b, odlikuje se Koši-Lorencovom distribucijom koju opisuje veoma sporo opadanje distribucije, pa se takođe definiše kao fat-tail distribution. Međutim, Loretz šum obuhvata i uzan deo oko krajnjih granica spektra [12]. U pojedinoj literaturi u okviru Lorentz šuma se definiše i Salt \& 
Papper šum [13, 14], međutim, sa Grafikona 3a se jasno može uočiti razlika između ova dva predstavljena šuma. Salt \& Papper šum se definiše sa dve eksponencijalne funkcije u krajevima spektra $[15,16]$, za razliku od veoma uzanog spektra kod Lorentz šuma. Primer slike sa postojanjem ova dva pomenuta šuma se nalazi na Slici 3.

\section{METODOLOGIJA}

Veoma dobru osnovu za obradu podataka i prikaz jednog dela rezultata mogu se naći u modifikovanoj verziji Robusne Multimodne Metode za detekciju i prepoznavanje lica koja se koristi u forenzici. Ova modifikovana verzija umesto baze za prepoznavanje lica i ključnih segmenata po kom se lica prepoznaju koristiće elemente koji su prikazani na Slici 4. a)

b)

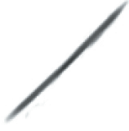

c)

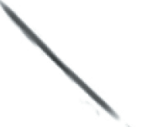

d)

e)

f)
Slika 4. Elementi za detekciju

Elementi za detekciju će u ovom slučaju biti predmet filtriranja median filtera [17], zajedno sa bližom okolinom. Podvrgavanje elemenata za detekciju samom filtriranju neće dati posebne rezultate, ali u odnosu na okolinu daće to da se redukuju "neželjeni” delovi slike. Zbog svojih karakteristika usrednjavanja vrednosti okoline piksela, izabran je Median filter. Pošto Median filter radi sa neparnim vrednostima podmatrica, zbog najmanje greške u radu pretpostavljene vrednosti okoline elemenata za detekciju su 3 piksela. Blok šema obrade slike prikazana je na Slici 5 .

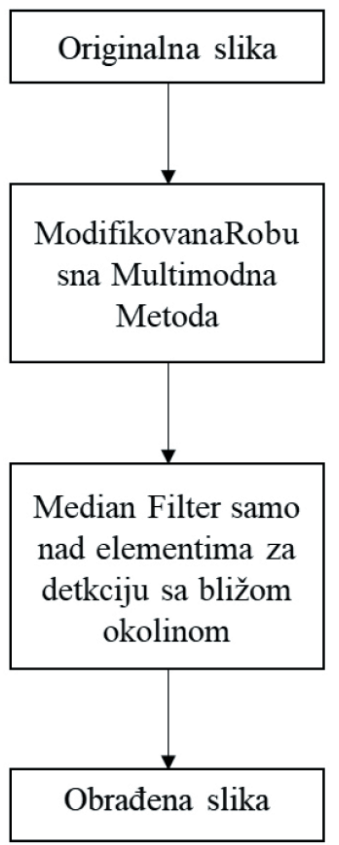

Slika 5. Blok šema obrade

Nakon ovog koraka može se pristupiti merenju koncentracije šuma koji se nalazi u originalnoj slici. Merenje se vrši jednostavnom metodom razlike dva signala (originalne i obrađene slike), a zatim se računa broj piksela nad kojima se vršila obrada. Rezultati su provereni i testirani kvantitativnom metodom na preko 50 slika sa različitom koncentracijom šuma i u formatu slike koji ne sadrži kompresiju, da bi se izbegao granični uslov da stepen kompresije može uticati na kvalitet slike, a samim tim i na rezultate. Takođe, $\mathrm{u}$ radu se pored kvantitativne metode koristila i kvalitativna, na taj način što je svaka slika posmatrana kroz relevantne parametre za ocenu kvaliteta digitalne slike.

\section{REZULTATI I DISKUSIJA}

Slika koja će predstavljati pokazni primer obrade i detekcije prirode Rain šuma prikazana je na Slici 6.

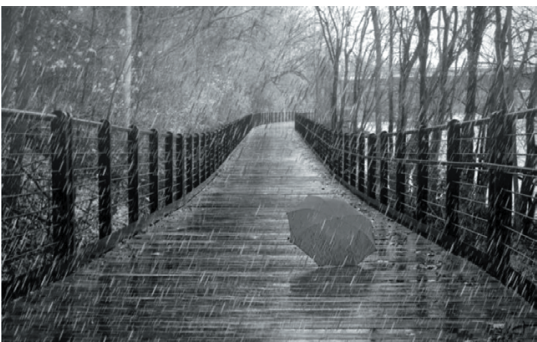

Slika 6. Originalna slika sa Rain tipom šuma 
Nakon primene modifikovane Robusne multimodne metode i unetim elementima kao na Slici 4, primeniće se parcijalno filtriranje Median filterom samo nad elementima za detekciju sa bližom okolinom od 3 piksela. Rezultati te obade prikazani su na Slici 7.

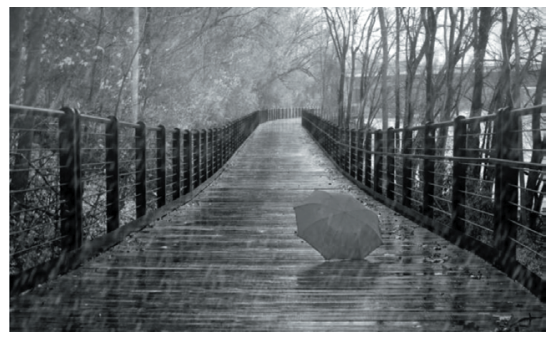

Slika 7. Originalna slika rekonstruisna sa modifikovanom Robusnom multimodnom metodom i parcijlno primenjenim Median filterom

Glavni cilj obrade ovog tipa je da se u bitnim segmentima slike ne gubi oštrina, odnosno da najveći deo ivica ostane istog ili veoma sličnog kvaliteta. Suštinski šum koji postoji u originalnoj slici će se definisati kao razlika između originalne i obrađene slike. Upotrebom parcijalnog filtriranja obrađen je samo šum, a ne ostali deo slike koji nije obuhvaćen šumom. Upravo zbog ove činjenice relevantno je da razlika signala originalne $i$ obrađene slike predstavlja šum. Tip i prirodu šuma moguće je objasniti nakon dobijenog histagrama razlike ove dve slike. Treba uzeti u obzir i grešku u detekciji i filtriranju koja može iznositi od 3-4,5\% [15, 16]. Histogram razlike predstavljen je na Slici 8 .

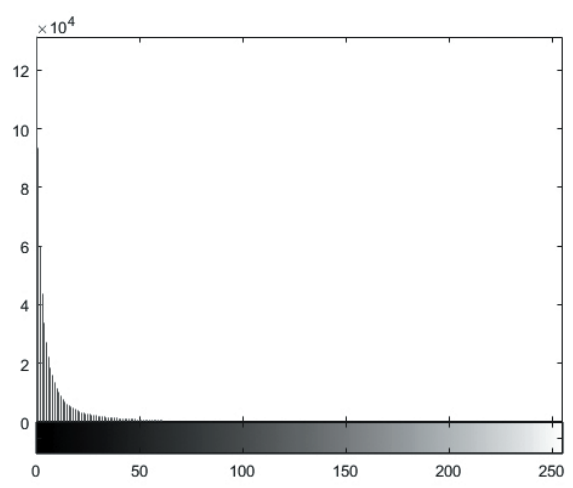

Slika 8. Histogram razlike Originalne slike i obrađene slike za Rain šum

Uporednom analizom Slike 3 i Slike 8 može se nedvosmisleno utvrditi da Rain šum ima elemente Salt \& Papper šuma, ali samo u donjem delu spektra.
Veoma je bitno reći da slika 6 u sebi sadrži $62,5 \%$ šuma, odnosno metodom parcijalnog filtriranja Median filterom obuhvaćen je taj procenat piksela. Što znači da je skoro $2 / 3$ slike obuhvaćeno obradom Median filtera sa podmatricom $3 \times 3$. Slika 9 daje prikaz kada se kompletna originalna slika podvrgne postupku filtriranja, da bi se uporedila razlika sa parcijalnim filtriranjem. Kao što se može uočiti, filter je "tretirao” kompletnu sliku i na taj način se redukovao veliki deo ivica. Pored vizuelnog dokaza da je parcijalno filtriranje neuporedivo bolje, numerički aspekt govori da je stepen detalja kod Slike 7 3,89 puta veći nego kod Slike 9 .

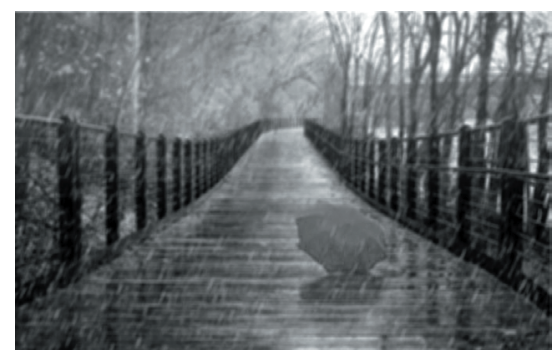

Slika 9. Originalna slika nakon primene Median filtera na celoj površini

Zbog obimnosti slika koje su upotrebljene u analizi, izabrane su reprezentativne za Snow \& Rain šum da bi se na adekvatan i sublimiran način prikazali rezultati ovog rada. Karakteristična slika koja reprezentuje Snow šum data je na Slici 10.

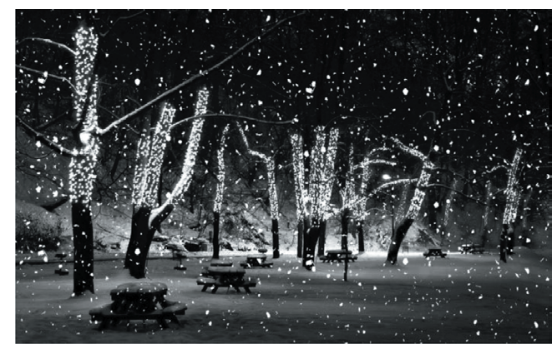

Slika 10. Originalna slika sa Snow tipom šuma

Nakon ponovljenog postupka kao u prethodnoj situaciji, odnosno primenom modifikovane Robusne multimodne metode i primenom Median filtera samo nad određenim segmentima slike, rezultati se mogu videti na Slici 11. 


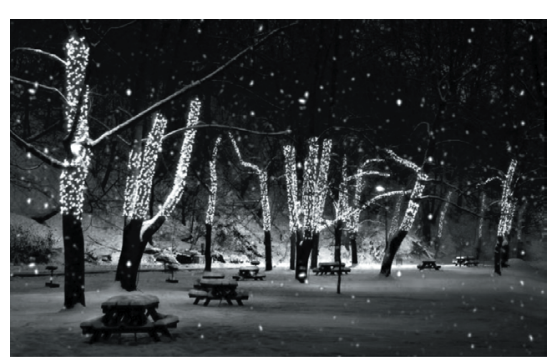

Slika 11. Originalna slika sa Snow tipom šuma nakon obrade pomenutom metodom

Kao u prethodnom slučaju, naveći deo ivica originalne slike nakon obrade je sačuvan i snaga Median filtera se koristila samo nad elementima koji su pretpostavljeni da predstavljaju šum sa bližom okolinom „tretiranih” piksela. Naravno, potrebno je napomenuti da kao u prethodnoj situaciji greška procene iznosi od 3-4.5\%.

Stepen šuma koji se nalazi na Slici 10 iznosi 21,2\% što znači da je praktično $1 / 5$ slike procesirana Medijan filterom, a ostali deo slike nije podvrgnut obradi. Bez obzira na ovako niži procenat šuma za razliku od Slike 6 , ovde je veoma bitno napomenuti da je priroda šuma veoma slična okruženu u kome se nalazi. Snežna idila u pozadini je iste ili slične boje kao i pahulje koje bi trebale da se procesiraju sa Medijan filterom. Ovde upravo snaga Robusne multimodne metode dolazi do izražaja jer detekcija elemenata koji su definisani u algoritmu predaće Medijan filteru samo one delove koji će se obraditi, a ostali deo slike (4/5 slike) neće biti obrađen. Sa druge strane, jako bitna činjenica kod parcijalnog filtriranja je upravo to što se ponaša u skladu sa definisanom situacijom.

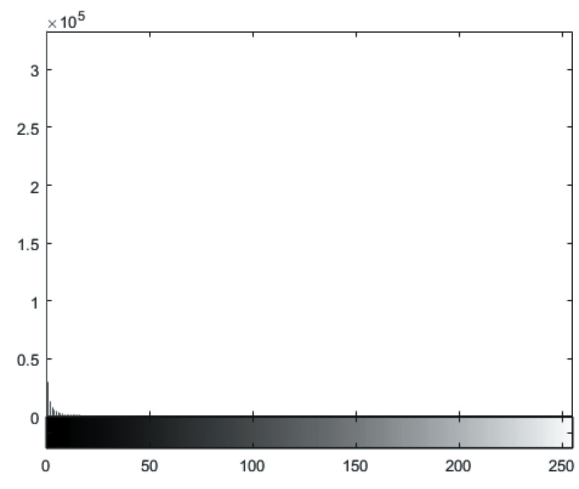

Slika 12. Histogram razlike originalne slike i obrađene slike za Snow šum
Primeri ostalih histograma razlike za testirane slike prikazani su na Slici 13. Kao što se može utvrditi sa slike, svi rezultati histograma daju potpuno isti oblik i podržavaju razmatranja slika koje su uzete kao pokazni primeri.
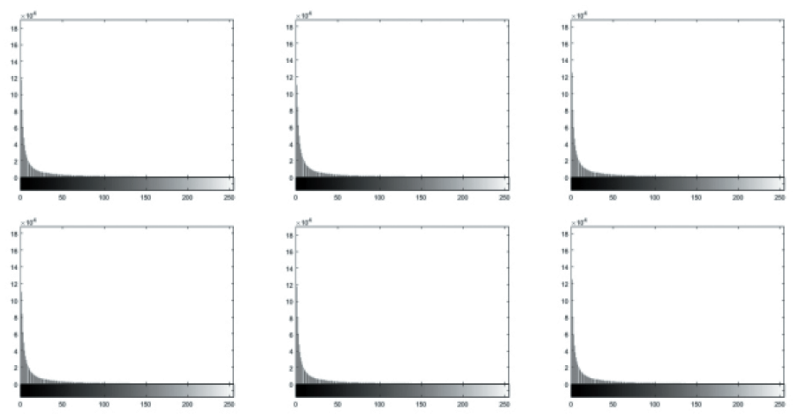

Slika 13. Histogram razlike originalne slike i obrađene slike za neke ostale slike u pocesu analize

Ako se vizuelno uporede rezultati sa Slike 3 i Slike 12, može se zaključiti da priroda Snow šuma ima elemente dva osnovna tipa šuma. Ono što je jako bitno napomenuti, Snow šum ne sadrži u sebi celokupno ponašanje Salt \& Papper i Lorencovog šuma, već samo njihove elemente. Po intenzitetu donje granice spektra Snow šum ima potpunu prirodu Lorencovog šuma, a po celom delu spektra u kome se pojavljuje ima prirodu leve poluperiode Salt \& Papper šuma. Zapravo se može definisati da je Snow šum - Salt šum sa Lorencovim intezitetom u donjem delu spektra.

\section{ZAKLJUČAK}

Rad je prezentovao analizu Rain \& Snow tipa šuma kroz metodu modifikovane Robusne multimodne metode i parcijalne primeme Medijan filtera. Tip šuma koji se javlja u uslovima nastanka kiše i snega podvrgnut je obradi i definisanju koncentracije šuma u slici. Pokazano je da metoda parcijalnog filtriranja može biti upotrebljena u postupku određivanja koncentracije šuma u digitalnoj slici. Utvrđeno je da Rain tip šuma sadrži samo Salt šum pa samim tim predstavlja donju poluperiodu Salt \& Papper šuma, dok Snow šum se takođe ponaša kao Rain po prirodi uz jedinu razliku da sadrži po intezitetu Lorencov šum u donjoj poluperiodi. Naredni koraci bi se kretali u modifikaciji primenjenog filtera $\mathrm{u}$ odnosu na detektovanu vrstu šuma. 


\section{ZAHVALNOST}

Ovaj rad je rađen u okviru projekta Implementation of the study program - Digital Broadcasting and Broadband Technologies (DBBT Master studies), Erasmus+ CBHE Project No. 561688-EPP-1-2015-1-XK-EPPKA2CBHE-JP.

\section{LITERATURA}

[1] L. Jong-Sen, „Digital Image Enhancement and Noise Filtering by Use of Local Statistics“, IEEE Transactions on Pattern Analysis and Machine Intelligence. IEEE Computer Society, vol. 2, no. 2, pp. 165-168, 1980.

[2] R. D. Edward, R. D. Random Processes for Image and Signal Processing. Chapter 1 - Probability Theory. Wiley-IEEE Press. Denver. USA, 1998.

[3] R. Ivković, M. Petrović, I. Milošević, B. Jakšić, R. Bojović, "Analysis of Different Edge Detections Algorithms Through the Bit-Plane Layers," in Sinteza 2017 - International Scientific Conference on Information Technology and Data Related Research, Belgrade, Singidunum University, Serbia, pp. 302-307, 2017.

[4] R. Ivković, M. Petrović, D. Miljković, P. Spalević, I. Milošević, "Reduction of Snow and Rain Noise in Spatial Domain," in Sinteza 2016 - International Scientific Conference on ICT and E-Business Related Research, Belgrade, Singidunum University, Serbia, pp. 287-292, 2016.

[5] R. Ivković, I. Milošević, T. Petrović, S. Bijelović, N. Ivković, "Analiza kvaliteta različitih formata digitalne slike," in Synthesis 2015 - International Scientific Conference of IT and Business-Related Research, Belgrade, Singidunum University, Serbia, pp. 171-175, 2015.

[6] F. Alessandro, T. Mejdi, K. Vladimir, E. Karen, E. „Practical Poissonian-Gaussian noise modeling and fitting for single image raw-data", IEEE Transactions on Image Processing, vol. 17, no.10, pp. 1737-1754, 2008.

[7] T. Le, R. Chartrand, T. J. Asaki, „A variational approach to reconstructing images corrupted by Poisson noise", Journal of Mathematical Imaging and Vision, vol. 27, no. 3, pp. 257-263, 2007.
[8] L. Florian, B. Thierry, U. Michael, „Image Denoising in Mixed Poisson-Gaussian Noise" IEEE transactions on image processing, vol. 20, no.3, pp. 696708, 2011.

[9] J. Portilla, V. Strela, M. J. Wainwright, E. P. Simoncelli, „Image denoising using scale mixtures of Gaussians in the wavelet domain", IEEE Trans. Image Process. vol. 12, no. 11, pp. 1338-1351, 2003.

[10] C. Keh-Shih, T. Hong-Long, C. Sharon, W. Jay, C. Tzong-Jer, „Fuzzy c-means clustering with spatial information for image segmentation" Computerized Medical Imaging and Graphics, vol. 30, no. 1, pp. 9-15, 2006.

[11] J. Lucas, V. Van, T. Y. Ian, L.B. Guus, „A nonlinear Laplace operator as edge detector in noisy images. Computer Vision" Graphics, and Image Processing, vol. 45, no. 2, pp. 167-195, 1989.

[12] E. Budevski, W. Obretenov, W. Bostanov, G. Staikov, J. Doneit, K. Jüttner, W. J. Lorenz, „Noise analysis in metal deposition-expectations and limits" Electrochimica Acta, vol. 34, no. 8, pp.1023-1029, 1989.

[13] V. R. Vijaykumar, P. T. Vanathi, P. Kanagasabapathy, D. Ebenezer, „High Density Impulse Noise Removal Using Robust Estimation Based Filter" IAENG - International Journal of Computer Science, vol. 35, no. 3, 2008.

[14] Z. Wang D. Zhang, „Progressive switching median filter for the removal of impulse noise from highly corrupted images", IEEE Transactions on Circuits and Systems II, vol. 46, no. 1, pp. 78-80, 1999.

[15] A. Bovik, Handbook of Image and Video Processing, New York: Academic, New York, USA, 2000.

[16] R. C. Gonzalez, R. E. Woods, Digital Image Processing, 2nd ed. Upper Saddle River, Prentice-Hall, New York, USA, 2001.

[17] I. Milosevic, R. Ivkovic, T. Petrovic, N. Denic, B. Jaksic, „Face Recognition through Robust Multimodal Biometric System with Sobel Edge Detection", International Scientific Conference "UNITECH 2015”, Gabrovo, Bulgaria, 20-21, November 2015, Proceedings, vol. 2, pp. II346-II351, 2015. 